\title{
PHYSICAL ACTIVII
}

Revision of two test items of the dutch motor skills assessment measuring
control in young table tennis players: a reproducibility and validity study

$\begin{array}{ll}\text { Autor(es): } & \text { Faber, Irene R.; Elferink-Gemser, Marije T.; Oosterveld, Frits G. J.; } \\ \text { Nijhuis-Van der Sanden, Maria W. G. }\end{array}$

Publicado por: Imprensa da Universidade de Coimbra

URL

persistente:

URI:http://hdl.handle.net/10316.2/34971

DOI:

DOI:http://dx.doi.org/10.14195/2182-7087_5_10

Accessed : $\quad$ 26-Apr-2023 09:22:08

A navegação consulta e descarregamento dos títulos inseridos nas Bibliotecas Digitais UC Digitalis, UC Pombalina e UC Impactum, pressupõem a aceitação plena e sem reservas dos Termos e Condições de Uso destas Bibliotecas Digitais, disponíveis em https://digitalis.uc.pt/pt-pt/termos.

Conforme exposto nos referidos Termos e Condições de Uso, o descarregamento de títulos de acesso restrito requer uma licença válida de autorização devendo o utilizador aceder ao(s) documento(s) a partir de um endereço de IP da instituição detentora da supramencionada licença.

Ao utilizador é apenas permitido o descarregamento para uso pessoal, pelo que o emprego do(s) título(s) descarregado(s) para outro fim, designadamente comercial, carece de autorização do respetivo autor ou editor da obra.

Na medida em que todas as obras da UC Digitalis se encontram protegidas pelo Código do Direito de Autor e Direitos Conexos e demais legislação aplicável, toda a cópia, parcial ou total, deste documento, nos casos em que é legalmente admitida, deverá conter ou fazer-se acompanhar por este aviso. 
(5) 2014

\section{ANNALS OF \\ RESEARCH IN SPORT AND \\ PHYSICAL ACTIVITY}

FACULDADE DE

CIÊNCIAS DO

DESPORTO E

EDUCAÇÃO FÍSICA DA UNIVERSIDADE DE COIMBRA

IMPRENSA

DA UNIVERISDADE

DE COIMBRA :

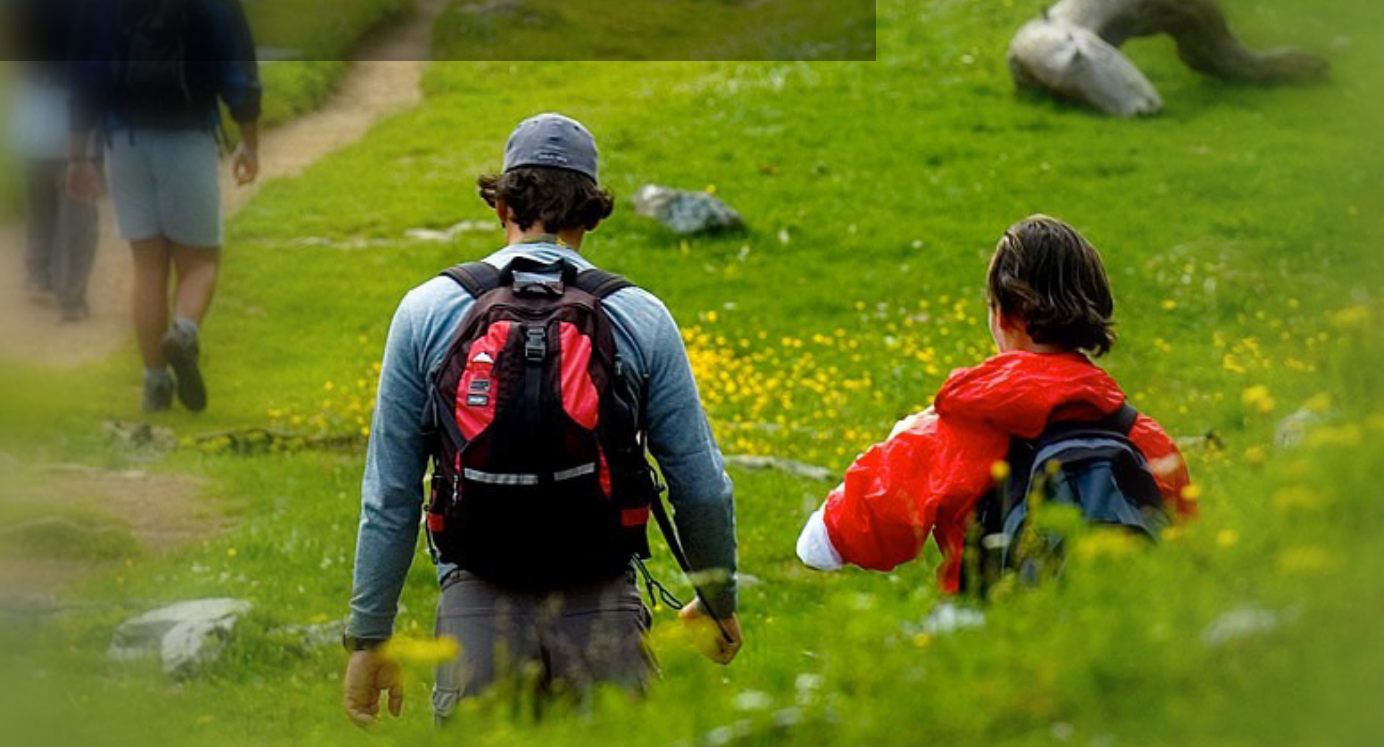


1 • TREINO DESPORTIVO / SPORT TRAINING REVISION OF TWO TEST ITEMS OF THE DUTCH MOTOR SKILLS ASSESSMENT MEASURING BALL CONTROL IN YOUNG TABLE TENNIS PLAYERS A REPRODUCIBILITY AND VALIDITY STUDY 

Irene R. Faber ${ }^{1}$, Marije T. Elferink-Gemser2,3, Frits G.J. Oosterveld', Maria W.G. Nijhuis-Van der Sanden ${ }^{4}$

REVISION OF TWO TEST ITEMS OF THE DUTCH MOTOR SKILLS ASSESSMENT MEASURING BALL CONTROL IN YOUNG TABLE TENNIS PLAYERS - A REPRODUCIBILITY AND VALIDITY STUDY

\section{RUNNING HEAD: REVISION OF TEST ITEMS ON BALL CONTROL IN YOUNG TABLE TENNIS PLAYERS}

\section{Corresponding author:}

Irene R. Faber, Faculty of Physical Activity and Health, Saxion University of Applied Sciences, P.O. Box 70.000, 7500 KB Enschede, The Netherlands. Phone: +31 620030686. E-mail: i.r.faber@saxion.nl.

Number of tables: 4

Number of figures: 5

\footnotetext{
1 Faculty of Physical Activity and Health, Saxion University of Applied Sciences, Enschede, The Netherlands, i.r.faber@saxion.nl; f.g.j.oosterveld@saxion.nl.

2 Center for Human Movement Sciences, University Medical Center Groningen, University of Groningen, Groningen, The Netherlands, Marije.Elferink@han.nl

${ }^{3}$ Institute for Studies in Sports and Exercise, HAN University of Applied Sciences, Nijmegen, The Netherlands

${ }^{4}$ Scientific Institute for Quality of Healthcare, Radboud University Medical Centre, Nijmegen, The Netherlands Ria.Nijhuis-vanderSanden@radboudumc.nl
} 


\section{ABSTRACT}

In a previous study the Dutch Motor Skills Assessment (MSA), including eight perceptuo-motor tasks, was investigated as a tool for talent development in table tennis. It appeared that two test items, 'aiming at target' and 'ball skills', needed revision due to irreproducible outcomes. In cooperation with expert trainers of the Netherlands Table Tennis Association new protocols were developed. This study evaluated the reproducibility of the revised test items by means of a test-retest design, and validity by testing the discriminative capacity using a known-group design and the correlation between test outcomes and competition results. Forty-three young table tennis players (6-13 years) from national $(n=16)$, regional $(n=12)$ and local training centres $(n=15)$ participated in this study. Twenty-seven players from the regional and local training centre were retested on the same day. ICC's for 'aiming at target' and 'ball skills' were 0.84 $(p<0.001)$ and $0.89(p<0.001)$, respectively, with coefficients of variation $<20 \%$ for both items. Mean outcomes of both revised test items demonstrated the same tendency; mean scores of players from the national centre were the highest, mean scores of regional centre players second highest, and mean scores of local centre players lowest. An ANCOVA using age as covariate and including Sidak post hoc tests, showed that players from the national and local training centre scored significantly differently on both test items $(p<0.05)$ and regional and local players scored significantly differently on 'ball skills' $(p<0.05)$. Moreover, a moderate but significant association between the results of 'aiming at target' and competition outcome $(R=0.53 ; p=0.003)$ was found. The results of 'ball skills' were not significantly related to competition $(R=0.22 ; p=0.249)$. Results suggest that the revision resulted in two sufficiently reproducible and valid test items. Longitudinal studies should be conducted to evaluate the predictive value of the test items when incorporated in the MSA.

Keywords: Reproducibility of results; Psychomotor performance; Aptitude; Racquet sports; Gifted children 


\section{INTRODUCTION}

Table tennis is one of world's fastest sports in terms of game speed and challenges for a player's capability of controlling the ball under great time pressure and constantly changing conditions. These conditions are related to the large variety of the flight and rotation of the upcoming ball, the player's intended return, playing styles and bat materials. High performance in table tennis strongly depends on visual perception and acuity, anticipation, and eye-hand coordination (Ak \& Koçak, 2010; Akpinar, Devrilmez, \& Kirazci, 2012; Bootsma, Fernandez, Morice, \& Montagne, 2010; Faber, Oosterveld, \& Nijhuis-Van der Sanden, 2014; Rodrigues, Vickers, \& Williams, 2002). All skills need to be extremely well developed and perfectly integrated in stroke techniques, fast and flexible footwork, proper positioning, and balance control (German Table Tennis Association, 2008; Horsch, 1990). Naturally, other qualities such as game-understanding, tactical skills, ability to make decisions, creativity, concentration, competitiveness, volition, and self-management must also be highly developed to outclass in table tennis (Chu, Chen, Chen, Huang, \& Hung, 2012; Liu, Zhou, Ji, \& Watson, 2012; Lopez \& Santelices, 2012; Raab, Masters, \& Maxwell, 2005). Nevertheless, if a player is not able to control the ball in an outstanding way, he may disqualify himself to develop into an elite player. Consequently, formulating criteria for ball control in a Motor Skills Assessment (MSA) as a part of a talent development programme to assess a player's potential seems logical and maybe even fundamental (Faber, Nijhuis-Van der Sanden, \& Oosterveld, 2013; Faber et al., 2014; Van Rossum \& Gagné, 1994).

In a previous study, the MSA of the Netherlands Table Tennis Association (NTTA) was evaluated as a tool for talent development in table tennis (Faber et al., 2013). This MSA includes eight test items (Table 1) intending to measure underlying perceptuo-motor skills considered requisite to the ability to develop adequate technical qualities in table tennis. Future potential is believed to be estimated more adequately by assessing such hypothesized essential perceptuo-motor skills under varying circumstances, which performance is not influenced by the quantity of training, rather than by assessing specific sport skills (Faber et al., 2013; Faber et al., 2014; Gagné, 2004; Vaeyens, Lenoir, Williams, \& Philippaerts, 2008; Vandorpe, Vandendriessche, Vaeyens, Pion, Matthys, Lefevre, Philippaerts, \& Lenoir, 2012). Perceptuo-motor skills are assessed in young table tennis players (6-13 year) as part of a talent development programme, because the necessary technical skills are suggested to be learned best from approximately five years till the pubertal growth (12-14 years) (Stang \& Story, 2005) by using the sensitive period for learning motor skills (Knudson, 2004; Limoochi, 2006; Watanabe, Savion-Lemieux, \& Penhune, 2007). It is expected that critical time will be lost influencing the potential end level when training to become an elite player starts at a later point in time.

The principal component analyses of the MSA's first evolution demonstrated that five of the eight test items loaded on the latent variable 'ball control' and three test items on 'gross 
motor function'. Moreover, it showed fair to good reproducibility, apart from the test items 'aiming at target' and 'ball skills', both connected to 'ball control'. The test item 'aiming at target' tested whether young players were able to alternately hit two square targets on the floor ( 2 and $4 \mathrm{~m}$ distance) using their own bat. Each player had six attempts and each hit counted for 4 points. The total score was registered the final outcome (Netherlands Table Tennis Association, 2011). With regard to the test item 'ball skills', players were instructed to alternately throw a ball with one bounce into two baskets on the floor ( 2 and $3 \mathrm{~m}$ distance). Each player had a total of twelve attempts, using a basketball in the first four attempts, a tennis ball in the following four attempts and a table tennis ball in the final four attempts. Each hit counted for 5 points, the total score of all attempts was registered as final outcome (Netherlands Table Tennis Association, 2011). The results of both 'aiming at target' and 'ball skills' were unstable and seemed to be based on coincidence too strongly ('aiming at target' ICC 0.525 ( $p<0.01$ ), CV 26\%; 'ball skills' ICC 0.311 ( $p<0.05)$, CV 43\%). Additionally, analyses regarding internal consistency showed that deleting the item 'ball skills' would even increase the internal consistency of the MSA. Yet, removing the two test items would violate the construct validity of the MSA by the absence of essential perceptuomotor skills assessing specific aspects of ball control (Faber et al., 2013). The other three items do not specifically cover aiming tasks, including an elongated arm (bat) and scaling ball direction. They focus on ball control in a dynamic situation ('speed while dribbling'), in combination with arm speed ('throwing a ball'), and in a repetitive movement task ('eyehand coordination'). Consequently, there is an indication for the revision of the test items 'aiming at target' and 'ball skills' in order to gain more trustworthy results in future.

Table 1. Current test items of the Dutch MSA (Motor Skills Assessment) (Netherlands Table Tennis Association, 2011).

Short description

Sprint

Agility

Vertical jump

Speed while dribbling

Aiming at target

Ball skills

Throwing a ball

Eye hand coordination
Pick-up and bring back 6 table tennis balls as fast as possible (pyramid shape sprint)

Getting through a circuit as fast as possible; over a gymnastics cabinet and under a low hurdle.

Jumping as high as possible.

Sideward dribbling through a zigzag circuit.

Aiming at a target with bat and ball.

Aiming a a target with different balls (football, tennis ball, table tennis ball) using one bounce.

Throwing a table tennis ball as far as possible.

Throwing and catching a table tennis ball against a vertical table as often as possible in 30 seconds using alternatively the left and right hand. 
New test protocols for the two test items were developed in cooperation with the expert trainers of the NTTA while taking the following recommendations for revision made by Faber et al. (2013) into account: more attempts, fewer variations in subtasks and a more extensive scale for the target. These recommendations were thought to provide more constant results, while maintaining sufficient responsiveness. Additionally, the expert trainers' main task was to preserve the nature of the test-item in assessing the intended specific perceptuo-motor skills to maintain the proposed construct of the MSA. The revised test items were developed for young table tennis players (6-12 years) and practical feasibility aspects were taken into account. After several trials and discussions, new test protocols were proposed for both test items and put under investigation to evaluate their reproducibility, discriminative validity, and concurrent validity in this study. In line with a previous study (Faber et al., 2013), the reproducibility was hypothesized to be at an acceptable level due to the inclusion of a training-phase, less variation in subtasks, a target with a centre and outer circle, and several attempts (Faber et al., 2014; Morrow, Jackson, Disch, \& Mood, 2011). Moreover, it was expected that the test items could discriminate players from apparent different training levels and a positive moderate significant associations ( $r$ between 0.4 and 0.7 ) between test and performance results (concurrent validity) existed in young table tennis players. Assuming that the revised test items demonstrate acceptable reproducibility and validity, they will eventually be included in the NTTA's MSA and will be evaluated in further detail with regard to their value for talent development.

\section{MATERIALS AND METHODS}

\section{Study design}

This study used a test-retest design to examine reproducibility. The initial test and retest were conducted on the same day with a minimum time of one hour and a maximum time of two hours between the tests. Additionally, the design to evaluate the validity served two purposes. First, both revised test items were evaluated with regard to their expected ability to discriminate between young table tennis athletes from national, regional and local training level, using the so-called 'known group method' (Portney \& Watkins, 2009). Secondly, the associations between the results of the revised test items and competition outcome were examined. The study was conducted in full compliance with the Declaration of Helsinki. The study protocol and informed consent procedures were approved by the Ethics Committee of the Medical Spectrum Twente (Medical School Twente, Institute for Applied Science, Enschede, the Netherlands; MTC/12307.fab 2-10-2012). 


\section{Players}

Young players were recruited from the national and a regional training centre of the NTTA and at a local table tennis centre. Players at the national training centre were selected by expert trainers of the NTTA and were suggested to be the high potential players at that moment throughout the Netherlands. The players of the regional training were selected by the NTTA trainers of the department for the eastern part of the country, and were considered to be the high potential players of that region. The young players from the local training centre were currently considered insufficiently skilled at this point in time, nor are they expected to be selected for a regional and/or national training centre of the NTTA in the future. Inclusion criteria were: an age between 6-13 years and being a member of a table tennis club connected to the NTTA. Children with injuries were excluded. Written informed parental consent and player assent were obtained prior to the testing.

\section{Measurements}

The standardization of the revised test items was covered in a protocol, which included a detailed description of the materials, set-up, assignment, demonstration, training phase, testing phase and recording test scores.

\section{Aiming at target - revised}

The player needed to hit a round target $(\varnothing 0.60 \mathrm{~m}$ ) on the floor at $2.5 \mathrm{~m}$ distance with a table tennis ball using a standard bat (Fig. 1a). Forehand and backhand need to be used alternately during the ten attempts. During the training phase the players practised hitting four times. A hit in the centre $(\varnothing 0.20 \mathrm{~m})$ or the outer ring of the target yielded 6 and 4 points, respectively. The total score of ten attempts was registered as the final outcome. The total time for testing was about 3 minutes per player (Netherlands Table Tennis Association, 2012).

\section{Ball skills - revised}

The player needed to hit a round target $(\varnothing 0.75 \mathrm{~m})$ on the floor via a table tennis table in vertical position by throwing a table tennis ball (Fig. 1b). The player had to alternately stand at a $1 \mathrm{~m}$ (Fig. 1b: A) and $2 \mathrm{~m}$ (Fig. 1b: B) distance from the target. Each player had a total of twenty attempts. During the training phase the players practised six times. A hit in the centre $(\varnothing 0.335 \mathrm{~m})$ or the outer ring of the target yielded 2 and 1 points, respectively. The total score of the twenty attempts was registered as the final outcome. The total time for testing was about 3 minutes per player (Netherlands Table Tennis Association, 2012). 

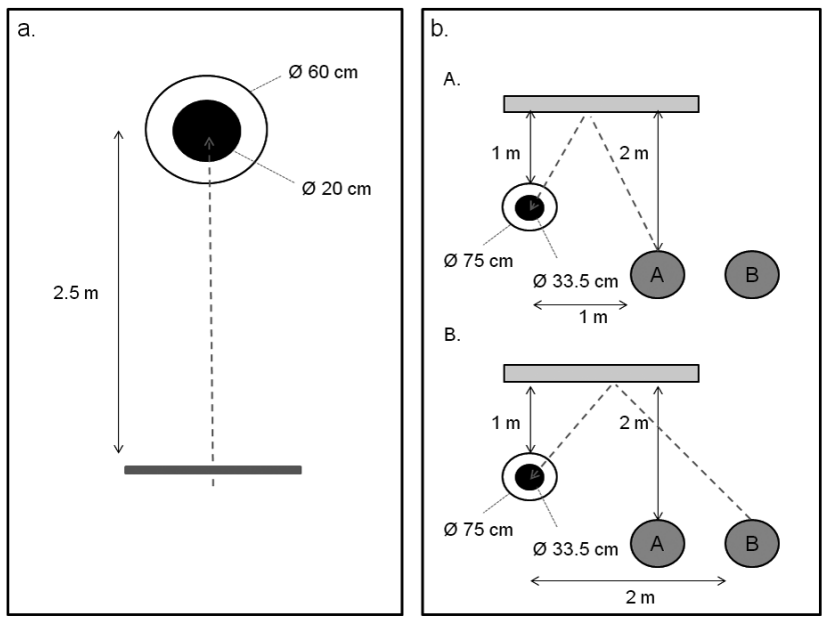

Figure 1. Ground map revised test protocols 'aiming at target' (a) and 'ball skills'(b).

Gray dotted arrows refer to the trajectory of the table tennis ball during an optimal hit or throw. At 'ball skills' the athlete stands alternately at a position of $1 \mathrm{~m}$ (Figure $1 \mathrm{~b}: \mathrm{A}$ ) and $2 \mathrm{~m}$ (Figure $1 \mathrm{~b}$ : B) from the target.

\section{PROCEDURE}

All players were assessed under similar conditions during a regular training session at their own training centre on a Sunday morning. Prior to testing, all participants did a warming up as part of their training. After warming up, the children started with the specific table tennis training and were invited to participate in the tests in pairs. After the tests, the players returned to their training. The testers were physiotherapy students who were trained to the same extend in using the test protocols. The players from the regional and local training centres were recruited for retesting by a different tester on the same day to estimate reproducibility. The retest was carried out by a different tester as different trainers conduct the tests in daily practice (Streiner \& Norman, 2003). Performance results i.e. competition outcome (points) and an estimation of their training hours per week were provided by the NTTA.

\section{Statistical analysis}

IBM Statistics 21 for Windows (IBM Corp., Armonk, New York, United States of America) was used for the statistical analyses. Normality of the test outcomes was evaluated by using 
the Shapiro-Wilk test. Possible differences in group characteristics between the players from the different training centres were tested using a one-way ANOVA including Sidak post-hoc tests and a chi-square test for ratio type data and frequencies, respectively.

Reproducibility was used as an umbrella term for both reliability and agreement (De Vet et al., 2006). Both reliability and agreement analyses were conducted on the final outcomes of each test-item. Intraclass correlation coefficients (ICC) based on the two-way random model (type consistency) and the 95\% confidence intervals were calculated as reliability parameters, because the MSA is used as a discriminative instrument and the main interest is to rank players (De Vet, Terwee, Knol, \& Bouter, 2006). The single measurement outcomes were used for all ICC calculations. ICC's of 0.7 or more are considered to be acceptable with regard to reliability on test item level (Nunally \& Bernstein, 1994). For the agreement parameters the standard error of measurement (SEm), smallest detectable differences (SDD), and coefficient of variation (CV) were calculated on the basis of the following formula's (De Vet et al., 2006; Hopkins, 2000):

$$
\begin{aligned}
& \mathrm{SEm}=\mathrm{SD}_{\text {difference_test-retest }} / \sqrt{ } 2, \\
& \mathrm{SDD}=1.96 \cdot \sqrt{2} \cdot \mathrm{SEm}, \\
& \mathrm{CV}=\mathrm{SEm} / \text { mean } \bullet 100 \% .
\end{aligned}
$$

These calculations are consistent with the selection of the reliability parameters. Moreover, Bland-Altman plots were used to provide a visual representations of measurement errors against true values by plotting the mean of initial test and retest scores versus the difference between the initial test and the retest values (Bland \& Altman, 1986).

For the first part of the validity analysis, ANCOVA and Sidak post-hoc tests were used per revised test item to test whether the items could discriminate between the players from the three different training centres. The test outcomes were used as dependent variables, the type of training centre as fixed factor, and age as a suggested covariate. The relations between the test scores of the two test items and the competition outcomes were evaluated in the second part of the validity analysis using partial correlation coefficient to correct for the influence of age. Training experience was considered a characteristic of the training centres included, and proved to be inadequate as independent covariate with regard to both validity analyses (Faber et al., 2014). Alpha was set at 0.05 for significance for all analyses.

\section{RESULTS}

A total of 43 young table tennis players (age 6-13 years) from national $(n=16)$, regional $(n=12)$ and local training-level $(n=15)$ participated in this study (Table 2). This included all players of the national training centre and the regional training centre of the department for the eastern part of the country at that moment. Seven of the players from the local cen- 
tres did not compete in official NTTA competitions. The data of three players with regard to left- or right-handedness were missing. The group characteristics of the three training centres did not differ significantly concerning sex, age, height, weight, and left- or righthandedness $(p>0.05)$. The number of hours of training per week and competition points on the other hand, differed significantly between the three groups $(p<0.001)$. The test outcomes of the revised test items of each training centre were distributed normally; $p$-values of the Shapiro-Wilk tests were $>0.05$ for the data of both test items.

Table 2. Characteristics of participating young table tennis players.

\begin{tabular}{|c|c|c|c|c|}
\hline & Total & National & Regional & Local \\
\hline Total & 43 & 16 & 12 & 15 \\
\hline Boys & 22 & 8 & 6 & 8 \\
\hline Girls & 21 & 8 & 6 & 7 \\
\hline Age (years) & $10.7 \pm 1.5$ & $10.9 \pm 1.4$ & $10.6 \pm 0.8$ & $10.7 \pm 2.0$ \\
\hline 6 year olds & 1 & - & - & 1 \\
\hline 7 year olds & 1 & - & - & 1 \\
\hline 8 year olds & - & - & - & - \\
\hline 9 year olds & 6 & 3 & 1 & 2 \\
\hline 10 year olds & 8 & 4 & 3 & 1 \\
\hline 11 year olds & 14 & 3 & 7 & 4 \\
\hline 12 year olds & 9 & 4 & 1 & 4 \\
\hline 13 year olds & 4 & 2 & 0 & 2 \\
\hline Height $(\mathrm{cm})$ & $148 \pm 11$ & $147 \pm 9$ & $148 \pm 10$ & $150 \pm 14$ \\
\hline Weight (kg) & $37 \pm 8$ & $33 \pm 6$ & $37 \pm 9$ & $39 \pm 9$ \\
\hline Right-handed & 32 & 13 & 8 & 11 \\
\hline Left-handed & 8 & 3 & 2 & 3 \\
\hline Training (hours/week) & $6(1-20)$ & $9(5-20)$ & $6(4-8)$ & $2(1-5)$ \\
\hline Competition (points) & $214(16-480)$ & $304(163-480)$ & $172(44-279)$ & $82(16-224)$ \\
\hline
\end{tabular}

Data are frequencies, except for age, height, and weight (mean \pm SD), and training and competition (mean (range)).

Figure 2-5, and Table 3 summarize the reproducibility outcomes. The Bland-Altman plots (Fig. 2; Fig. 4) and the scatter plots (Fig. 3; Fig. 5) of both tests show by a positive mean difference and a positive intercept, that players tended to have higher scores at the retest than the initial test. The revised test items meet the criteria of an ICC $>0.7(p<0.05)$ for reliability (Nunally \& Bernstein, 1994). Furthermore, the agreement parameters show a 
SDD of 14.6 points and 6.3 points and CV of $19 \%$ and $14 \%$, respectively for the test items 'aiming at target' and 'ball skills.

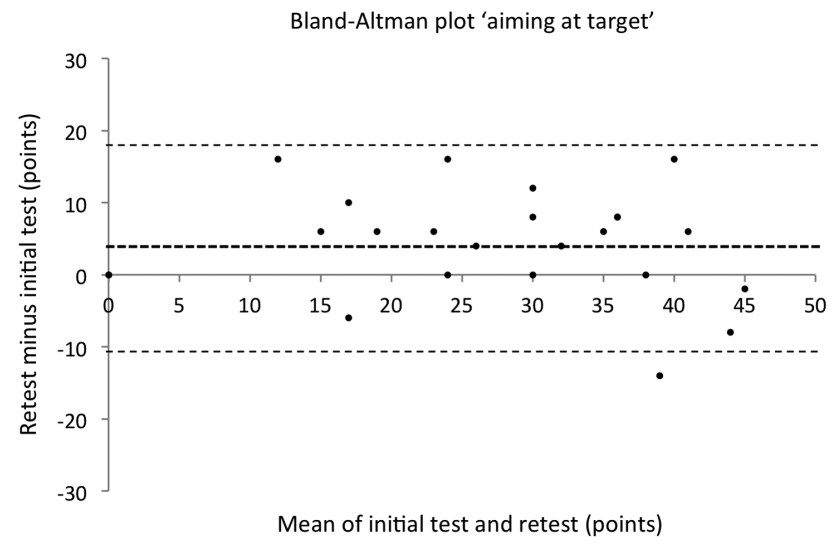

Figure 2. Bland-Altman plot for 'aiming at target'.

The bold dotted line represents the mean difference between the initial test and retest. The non-bold dotted lines represent the $95 \%$ limits of agreement ( $\pm 1.96 \bullet$ SD).

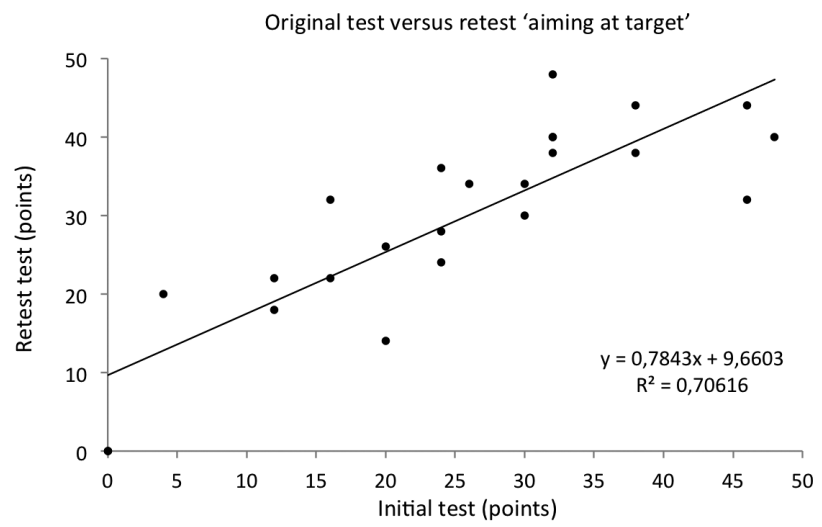

Figure 3. Original test versus retest 'aiming at target'. 


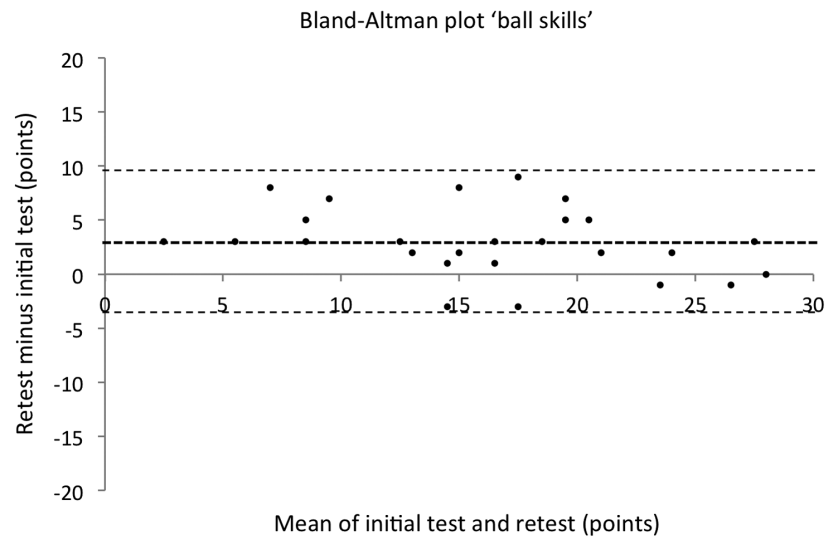

Figure 4. Bland-Altman plot for 'ball skills'.

The bold dotted line represents the mean difference between the initial test and retest. The non-bold dotted lines represent the $95 \%$ limits of agreement $( \pm 1.96 \bullet S D)$.

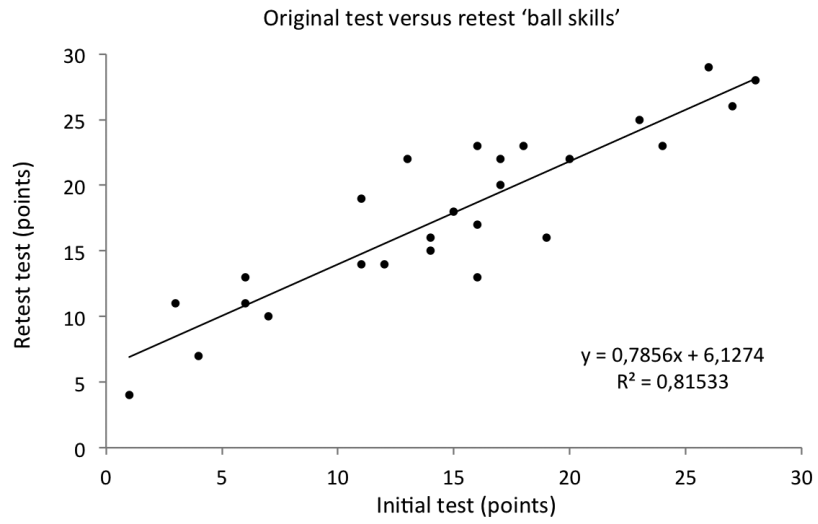

Figure 5. Original test versus retest 'ball skills'. 
Table 3. Reproducibility outcomes.

\begin{tabular}{lcccccc}
\hline Item & $\mathrm{n}$ & ICC & $\begin{array}{c}\text { ICC } \\
\text { 95\% confidence } \\
\text { interval }\end{array}$ & SEm & SDD & $\begin{array}{c}\text { CV } \\
(\%\end{array}$ \\
\hline $\begin{array}{l}\text { Aiming } \\
\text { at target } \\
\text { (points) }\end{array}$ & 24 & $0.838^{*}$ & $0.662-0.927$ & 5.3 & 14.6 & 19 \\
$\begin{array}{l}\text { Ball skills } \\
\text { (points) }\end{array}$ & 26 & $0.894^{*}$ & $0.779-0.951$ & 2.3 & 6.3 & 14 \\
\hline
\end{tabular}

n: number; ICC: Intraclass Correlation Coefficient (model: two-way random; type: consistency); SEm: Standard Error of measurement; SDD: smallest detectable difference; CV: coefficient of variation; * $p<0.001$.

The results of the validity analyses are presented in Table 4. For the two revised test items, there was a trend that the mean scores of the players from the national training centre were the highest, the mean scores of the players from the regional centre the second highest, and the players from the local training centre the lowest. The ANCOVA and Sidak post hoc, using age as a covariate, revealed that the players from the national and local centres scored significantly differently on the two revised items $(p<0.05)$, and the players from the regional and local centres had significantly different scores on 'ball skills' $(p<0.05)$. Furthermore, the revised item 'aiming at target' demonstrated a significant, moderate association between the test outcomes and competition results $(R=0.52, p=0.003)$, while controlling for age. Yet, no significant association was found between the test outcomes of 'ball skills' and the competition results $(R=0.22, p=0.249)$.

Table 4. Mean test outcome $( \pm S D)$ and results of validity analyses.

\begin{tabular}{lccccc}
\hline $\begin{array}{l}\text { Revised test } \\
\text { item }\end{array}$ & $\begin{array}{c}\text { National } \\
(n=13)\end{array}$ & $\begin{array}{c}\text { Regional } \\
(n=11)\end{array}$ & $\begin{array}{c}\text { Local } \\
(n=19)\end{array}$ & $\begin{array}{c}F(p) \\
(n=43)\end{array}$ & $\begin{array}{c}R(p) \\
(n=28)\end{array}$ \\
\hline $\begin{array}{l}\text { Aiming at } \\
\text { target }\end{array}$ & $37 \pm 8$ & $30 \pm 9$ & $22 \pm 15$ & $6.900 a(=0.003)$ & $0.52(=0.003)$ \\
Ball skills & $20 \pm 6$ & $18 \pm 6$ & $12 \pm 7$ & $7.444 a(=0.002)$ & $0.22(=0.249)$ \\
\hline
\end{tabular}

F: F-value of ANCOVA among the three groups.

R: Partial correlation coefficient of association between test and competition results controlled for age. a $p<0.05$ : Sidak post hoc tests showed significant differences between the national and local training centres for 'aiming at target' and between the national and local centres and between the regional and local centres for 'ball skills'.

\section{DISCUSSION}

The results of this study indicate that the revised test items 'aiming at target' and 'ball skills' are sufficiently reproducible and valid. The revision of the test items improved 
the stability of the test outcomes and thus the reliability and agreement parameters. Furthermore, the expected hierarchy was confirmed in the test outcomes of the players of the national, regional, and local training centre, and the revised test items are able to significantly discriminate national training centre players from the local training centre players while controlling for age. A significant difference was found between the players from the regional centre and players of local training centres with regard to 'ball skills' and a significant positive association was found between 'aiming at target' and competition performance. Consequently, both revised test items are suggested to suit the NTTA's MSA as part of their talent development programme by measuring specific aspects of ball control. The MSA, including the revised test items, must be evaluated further in a new sample with regard to its structure using a confirmatory factor analysis and with regard to its predictive value in a longitudinal design.

The reproducibility outcomes were satisfactory. Although some learning affect exists, players tended to have better results at the retest than the initial test, revisions in the test protocols ensured acceptable reliability for both items. The reliability parameters are now similar to the values of the other test items within the MSA (Faber et al., 2013) and other instruments (Ali et al., 2007; Girard \& Millet, 2009; Kiphard \& Schilling, 2007; Lemmink, Elferink-Gemser, \& Visscher, 2004; Vandorpe et al., 2012), which means that is possible to differentiate or rank young table tennis players by means of the revised test items to an acceptable extent (De Vet et al., 2006; Hopkins, 2000). Unfortunately no re-testing could be done at the national training centre. As a result of this, reproducibility analyses were not conducted on the basis of the total range in which the players scored. It is expected, however, that the reliability parameters in particular will improve even more by including players from the national centre by extending the range of the test scores (De Vet et al., 2006; Hopkins, 2000). The agreement parameters are also at an acceptable level. The remaining variability of the performance within the players is believed to be coherent with learning a new task. The SDDs show that to distinguish two players from each other based on the results of 'aiming at target' and 'ball skills', players must differ at least 15 and 7 points, respectively.

The ability of the test items to discriminate the national and local training centre players, and the difficulty to discriminate regional players from other players are in line with the findings of Faber et al. (2014). Also in this study, this may be explained by an overlap in the inclusion of children of the specific training centres with regard to motor performance. The large overlap of the competition points of the national and regional training centre players and of the regional and local players (Table 1) supports this. As proposed by Faber et al. (2014), this could be due to other selection criteria than motor performance (e.g. motivation, concentration, and self-management) for the regional and national training centres and environmental factors (e.g. parents). As a result, players with similar motor potential could be selected for different training centres. 
The concurrent validity of 'ball skills' was not confirmed in this study; only a low nonsignificant association with competition results was found instead of the hypothesized moderate association. The test item 'ball skills' assesses a player's ability to scale force, speed, and direction in order to realise an optimal ball flight for hitting a target using an untrained and non-sport-specific motor task, which was expected to result into a moderate association of the test outcomes and competition results. The lower association found is probably a consequence of the overlap between the players from the different training centres regarding motor performance combined with the absence of the competition results of seven players of the local training centre. These local players had low test scores, and are considered to be low performers. The lack of these data for the concurrent validity analysis and the overlap between the other players reduced the variety in the data and thus the correlation coefficient.

Although these aspects also apply to 'aiming at target', a significant, moderate association was found for this item. This higher significant association is suggested to be due to the greater consistency of this item with specific skills trained table tennis. It was our intention to assess underlying perceptuo-motor skills by using untrained and non-sport specific motor tasks (Faber et al., 2014; Gagné, 2004; Morrow et al., 2011; Vaeyens et al. 2008; Vandorpe et al., 2012). Although the exact task of 'aiming at target' in all probability is never trained, it included some aspects specific for table tennis (NTTA 2012): the use of a bat and a table tennis ball, and the distance from the target is similar to the distance on the table. This was due to the fact that the assessment of hitting accuracy at that specific distance using a bat is considered an essential perceptuo-motor skill by the expert trainers of the NTTA. The low and moderate correlation coefficients of the items 'balls skills' and 'aiming at target, respectively, may indicate that training influences were limited, but it remains unclear to which extent training experience could have influenced the test outcomes. Longitudinal studies are to reveal this as 'training experience' is not an independent covariate in this study.

Finally, acknowledging that this study included only a small sample is important. This is due to the fact that only a small number of talented table tennis players (best 1-5\%) is available, considered crucial for inclusion in this study to make a fair interpretation. Although only 43 players participated, it is believed to be a representative sample of young table tennis players and generalisation is possible for this subgroup. In addition, despite the small sample, we were able to find significant results for validity and reproducibility.

In conclusion, the results of this study indicate a satisfactory revision of the test items 'aiming at target' and 'ball skills' and contribute to an evidence-base talent development programme for table tennis and probably other racket sports. The revised protocols can be implemented in the NTTA's MSA as part of their talent development programme to maintain and reinforce the original construct. Further research to obtain reproducibility and normative data in a larger sample, and to learn more about the predictive 
value in longitudinal studies is essential for a good interpretation of individual test scores (Ackerman, 2013; Vaeyens et al., 2008; Vandorpe et al., 2012). Gender and maturity influences on individual performances should also be taken into account (Ackerman, 2013; Helsen, Winckel, \& Williams, 2005; Thomas \& French, 1985). In addition, it should be emphasized that the MSA only partly covers the fundament of high potentials. As in many other sports, psyhological, social and environmental factors are also believed to play crucial roles in talent development in table tennis (Elferink-Gemser, Jordet, Coelho-E-Silva, \& Visscher, 2011; Gagné, 2004). Moreover, the results of this study should not be used to limit the freedom of choice in children to practice (more than) a particular sport. Trainers and coaches should also be aware of the potential risks of early specialization and selection at such a young age (e.g. injuries, mental exhaustion and drop-outs) (Baker, Côté, \& Deakin, 2005; Wall \& Côté, 2007). The MSA is only intended as part of a talent development programme to identify those children that excel in perceptuo-motor skills essential for table tennis.

\section{ACKNOWLEDGMENTS}

The authors would like to thank all participants, their parents, the trainers of the national, regional, and local training centres, the physiotherapy students and the Netherlands Table Tennis Association for their cooperation. Financial support was provided by Saxion University of Applied Sciences and the Dutch Olympic Committee*Dutch Sports Federation in the context of a national talent identification project in sports.

\section{REFERENCES}

Ackerman, P. (2013). Nonsense, common sense, and science of expert performance: Talent and individual differences. Intelligence: In press.

Ak, E., \& Koçak, S. (2010). Coincidence-anticipation timing and reaction time in youth tennis and table tennis players. Percept Mot Skills, 110: 879-887.

Akpinar, S., Devrilmez, E., \& Kirazci, S. (2012). Coincidence-anticipation timing requirements are different in racket sports. Percept Mot Skills, 115: 581-593.

Ali, A., Williams, C., Hulse, M., Strudwick, A., Reddin, J., Lee, H., ... McGregor, S. (2007). Reliability and validity of two tests of soccer skill. J Sports Sci, 25:1461-1470.

Baker, J., Côté, J., \& Deakin, J. (2005). Expertise in ultra-endurance triathletes early sport involvement, training structure, and the theory of deliberate practice. J App/ Sport Psych, 17(1): 64-78.

Bland, J.M., \& Altman, D.G. (1986). Statistical methods for assessing agreement between two methods of clinical measurement. Lancet, 1: 307-310. 
Bootsma, R.J., Fernandez, L., Morice, A.H.P., \& Montagne, G. (2010). Top level players' visual control of interceptive actions: Bootsma and Van Wieringen (1990) 20 years later. J Exp Psychol Human, 36: 1056-1063.

Chu, C.Y., Chen, I.T., Chen, L.C., Huang, C.J., \& Hung, T.M. (2012). Sources of psychological states related to peak performance in elite table tennis players. International Journal of Table Tennis Sciences, 7 : 86-90.

De Vet, H.C.W., Terwee, C.B., Knol, D.L., \& Bouter, L.M. (2006). When to use agreement versus reliability measures. J Clin Epidemiol, 59: 1033-39.

Elferink-Gemser, M., Jordet, G., Coelho-E-Silva, M.J., \& Visscher C. (2011). The marvels of elite 393 sports: how to get there? Brit J Sport Med, 45: 683-684.

German Table Tennis Association. (2008). Koordinationstraining im tischtennis. Germany: German Table Tennis Association.

Faber, I.R., Nijhuis-Van der Sanden, M.W.G., \& Oosterveld, F.G.J. (2013). The Dutch talent identification assessment for table tennis; a reproducibility and validity study. Proceedings $18^{\text {th }}$ Annual Congress of the European College of Sport Science, Barcelona, Spain.

Faber, I.R., Oosterveld, F.G.J., \& Nijhuis-Van der Sanden, M.W.G. (2014). Does an Eye-Hand Coordination Test Have Added Value as Part of Talent Identification in Table Tennis? A Validity and Reproducibility Study. PLOS ONE, 9(1): e85657.

Gagné, F. (2004). Transforming gifts into talents; the DMGT as a developmental theory. High Abil Stud, 15(2): 119-147.

Helsen, W.F., Winckel, van J., \& Williams, A.M. (2005). The relative age effect in youth soccer across Europe. J Sport Sci, 23: 629-636.

Horsch, R. (1990). Tischtennis; Schule, Verein, Freizeit; Sport in der Lehrerfortbildung: Band 4 [Table tennis; school, club, leisure; Sports in teacher education: part 4]. Konstanz: Universitätsverlag Konstanz $\mathrm{GMBH}$.

Hopkins, W.G. (2000). Measures of Reliability in Sports Medicine and Science. Sports Med, 30(1): 1-15.

Kiphard, E.J., \& Schilling, F. (2007). Körperkoordinationstest für Kinder. 2. Überarbeitete und ergänzte Auflage. Weinheim: Beltz Test GmbH.

Knudsen, E. (2004). Sensitive periods in the development of the brain and behavior. J Cogn Neuro, 16: $1412-1425$.

Lemmink, K.A.P.M., Elferink-Gemser, M.T., \& Visscher, C. (2004). Evaluation of the reliability of two field hockey specific sprint and dribble tests in young field hockey players. Brit J Sports Med, 38: 138-142.

Limoochi, S. (2006). A survey of table tennis coaches' opinions of some criteria in talent identification. International Journal of Table Tennis Sciences, 6: 280-287.

Liu, W., Zhou, C., Ji, Z., \& Watson, J.C. (2012). The effect of goal setting difficulty on serving success in table tennis and the mediating mechanism of self-regulation. J Hum Kinet, 33: 173-185.

Lopez, A., \& Santelices, O. (2012). Personality characteristics of elite table tennis athletes of the Philippines: basis for a proposed recruitment program. International Journal of Table Tennis Sciences, 7: 1-4.

Morrow, J.R. Jr., Jackson, A.W., Disch, J.G., \& Mood, D.P. (2011). Measurement and evaluation in human performance (4th ed.). Champaign, IL: Human Kinetics.

Netherlands Table Tennis Association. (2011). Test protocols National Day of Talent. Zoetermeer: Netherlands Table Tennis Association. 
Netherlands Table Tennis Association. (2012). Revised test protocols National Day of Talent. Zoetermeer: Netherlands Table Tennis Association.

Nunally, J.C., \& Bernstein, I.H. (1994). Psychometric theory (3th ed.). New York: McGraw-Hill.

Portney, L.G., \& Watkins, M.P. (2009). Foundations of clinical research - applications to practice (3th ed.). Upper Sadle River New Jersey: Pearson Education.

Raab, M., Masters, R.S.W., Maxwell, J.P. (2005). Improving the 'how' and 'what' decisions of elite table tennis players. Hum Mov Sci, 24: 326-344.

Rodrigues, S.T., Vickers, J.N., \& Williams, A.M. (2002). Head, eye and arm coordination in table tennis. J Sport Sci, 20: 187-200.

Stang, J., \& Story, M. (Eds). (2005). Adolescent growth and development. Guidelines for adolescent nutrition services. Center for Leadership, Education and Training in Maternal and Child Nutrition, Division of Epidemiology and Community Health, School of Public Health. Minneapolis: University of Minnesota.

Streiner, D.L., \& Norman, G.R. (2003). Health Measurement Scales. A Practical Guide to their Development and Use. New York: Oxford University Press.

Thomas, J.R., \& French, K.E. (1985). Gender differences across age in motor performance: a meta-analysis. Psych Bull, 98: 260-282.

Vaeyens, R., Lenoir, M., Williams, A.M. \& Philippaerts, R.M. (2008). Talent Identification and Development Programmes in Sport. Current Models and Future Directions. Sports Med, 38(9): 703-714.

Vandorpe, B., Vandendriessche, J.B., Vaeyens, R., Pion, J., Matthys, S., Lefevre, J., Philippaerts, R.M., \& Lenoir, M. (2012). The value of a non-sport-specific motor test battery in predicting performance in young female gymnasts. J Sport Sci, 30(5): 497-505.

Van Rossum, J.H.A., \& Gagné, F. (1994). Rankings of predictors of athletic performance by top level coaches. European Journal for High Ability, 5: 68-78.

Wall, M., \& Cote, J. (2007). Developmental activities that lead to dropout and investment in sport. Physical Education and Sport Pedagogy, 12(1): 77-87.

Watanabe, D., Savion-Lemieux, T., \& Penhune, V.B. (2007). The effect of early musical training on adult motor performance: evidence for a sensitive period in motor learning. Exp Brain Res, 176 : 332-340. 